\title{
Electronic Collimation
}

National Cancer Institute

\section{Source}

National Cancer Institute. Electronic Collimation. NCI Thesaurus. Code C94891.

The use of coincidence with a pair of gammas giving a coincidence event in detectors 180 degrees apart in a PET scanner to define a line of response along which lies the location of the radiation emitting tracer. This differs from the use of slab collimators whose many holes define lines of response from a single gamma emission. 